\title{
Comments on current ratio-setting models for time perception
}

\author{
LORRAINE G. ALLAN \\ McMaster University, Hamilton, Ontario L8S 4K1, Canada
}

\begin{abstract}
This paper is concerned with the analysis and interpretation of ratio-setting data. Ratiosetting data have been used in support of the conclusion that time perception is not veridical. In the present paper, new ratic-setting data are presented and it is argued that the existing ratio-setting models do not allow the psychophysical law for time to be derived.
\end{abstract}

Eisler (1976) has recently published an impressive survey of 111 time perception studies employing the methods of ratio-setting and/or magnitude estimation. He concluded that time perception is not veridical, and that the psychophysical function relating subjective (internal) time to stimulus time is best described by the power law. He found that although the exponents estimated from these studies straddled unity, most were less than 1.00 , and he concluded that, on the average, the exponent for time is about .90.

In conflict with Eisler's conclusion that subjective time is a power function of stimulus time are the discrimination data which suggest that subjective time is a linear function of stimulus time. Many of the quantitative models for human duration discrimination assume that repeated presentation of the same stimulus duration results in a distribution of internal duration values. The models proposed by Allan and Kristofferson (1974), Creelman (1962), Getty $(1975,1976)$, and Kinchla (1972) differ regarding the form of the distribution and the relationship between the variance of the distribution and stimulus duration, but are similar in that the expected value of the distribution is a linear function of stimulus duration. (It should be noted that Getty's model is consistent with both a linear and a logarithmic relationship between the expected value and stimulus duration, but not with a power relationship).

Kristofferson (1977) has shown that under some circumstances duration discrimination can be interpreted as temporal order discrimination. His data are compatible with a model which places all of the

This research was supported by Grant $\mathbf{A} 8260$ from the National Research Council of Canada. The paper was written while I was on sabbatical at the University of Stirling, Stirling, Scotland. I would like to express my appreciation to the Psychology Deparment for providing a conducive atmosphere for scholarship. Requests for reprints should be sent to Lorraine G. Allan, Psychology Department, McMaster University, Hamilton, Ontario, L8S 4K1, Canada. variability in the criterion and none in the stimulus. This model, the real-time criterion model, states that there is no transformation of stimulus time into psychological time. Subjective time is real time.

Perhaps the most important difference between the ratio-setting literature and the duration discrimination literature is the model used to make inferences about the psychophysical law. The duration discrimination models are at least two-parameter models. There are always a discrimination parameter and a response bias or criterion parameter. The ratio-setting models proposed by Eisler (1975) and Ekman (1958, Note 1) are effectively one-parameter models.

Duration discrimination data are not the only indication that the transformation of stimulus time into subjective time is linear. Two recent studies using category ratings have produced data which indicate linear psychophysical functions. Both studies were concerned with developing a methodology for category ratings which would allow the emergence of the psychophysical law uninfluenced by "nonsensory" variables. Curtis and Rule (1977) analyzed their data in terms of a two-stage model for psychophysical judgments which has proved extremely useful in other situations (Curtis, Attneave, \& Harrington, 1968; Curtis \& Mullin, 1975). Blankenship and Anderson (1976) made use of the functional measurement approach (Anderson, 1977) and analyzed their data in terms of a weighted sum integration model.

This paper is concerned with the analysis and interpretation of ratio-setting data. Its major purpose is to demonstrate that the ratio-setting data are not in conflict with the duration discrimination data. Existing ratio-setting models do not allow the psychophysical function to be derived, and therefore cannot provide the necessary evidence to support the conclusion that time perception is not veridical.

In a ratio-setting task, a standard duration is presented to the subject, and he is required to set a variable duration so that it is some proportion, $P$, of the standard duration. By far the most extensive set of ratio-setting data for time has been reported 
by Eisler (1975). The 10 standard durations covered a range from 1.3 to $20 \mathrm{sec}$. Each of 12 subjects participated in three ratio-setting tasks. In the reproduction or equal-setting task, the subject was required to set the variable duration equal to the standard duration $(P=1)$; in the half-setting task, he was required to set the variable duration equal to half the standard duration $(P=1 / 2)$; and in the double-setting task, he was required to set the variable duration equal to twice the standard duration $(P=2)$. Eisler concluded that his ratio-setting data were strongly supportive of a power law for time with an exponent of about .85. However, it should be noted that the exponents estimated from each of the 12 subjects varied from about .50 to 1.30. Further, the correlation between the reproduction exponents and the half-setting exponents was only .14.

The exponent cannot be estimated directly from ratio-setting data, and therefore the estimated value depends upon the model adopted by the investigator. Let $s$ represent the subjective duration of the standard, and $v$ the subjective duration of the variable. It is usually assumed that in a ratio-setting task

$$
\mathrm{v}=\mathrm{ps},
$$

where $\mathrm{p}$ represents the ratio used by the subject, in contrast to $\mathrm{P}$, the ratio specified by the experimenter. None of the terms in Equation 1 are observable. What is observed is the relationship between the variable settings (V) and the standard durations (S). Most frequently, this empirical relationship has been found to be linear:

$$
\mathrm{V}=\mathrm{mS}+\mathbf{a}
$$

Eisler (1958) and Ekman (1958, Note 1) first showed that if Equation 1 is assumed, then the power function as the psychophysical law was compatible with the empirical linear relationship between the variable duration and the standard duration.

If the psychophysical function is a power function with exponent $n$, then

$$
\mathrm{v}=\mathrm{k}_{\mathrm{v}}\left(\mathrm{V}-\mathrm{c}_{\mathrm{v}}\right)^{\mathrm{n}}
$$

and

$$
\mathrm{s}=\mathrm{k}_{\mathrm{s}}\left(\mathrm{S}-\mathrm{c}_{\mathrm{s}}\right)^{\mathrm{n}}
$$

where $k_{s}, k_{v}, c_{s}$, and $c_{v}$ are scale parameters. Substituting Equations 3 and 4 in Equation 1 and rearranging terms,

$$
\mathrm{V}=\mathrm{S}\left[\frac{\mathrm{pk}_{\mathrm{s}}}{\mathrm{k}_{\mathrm{v}}}\right]^{1 / \mathrm{n}}-\mathrm{c}_{\mathrm{s}}\left[\frac{\mathrm{pk}_{\mathrm{s}}}{\mathrm{k}_{\mathrm{v}}}\right]^{1 / \mathrm{n}}+\mathrm{c}_{\mathrm{v}}
$$

For $\mathrm{k}_{\mathrm{v}}=\mathrm{k}_{\mathrm{s}}$ and $\mathrm{c}_{\mathrm{v}}=\mathrm{c}_{\mathrm{s}}=\mathrm{c}$, Equation 5 simplifies to

$$
\mathrm{V}=\mathrm{Sp}^{1 / \mathrm{n}}+\mathrm{c}\left(1-\mathrm{p}^{1 / \mathrm{n}}\right) .
$$

The value of $n$ cannot be estimated from the empirical relationship between variable duration and standard duration (Equation 6) without making an assumption about the relation of $p$ to P. Eisler $(1974,1975$, 1976), Ekman (1958), Frankenhaeuser (1960), Eisler (Note 2), Ekman (Note 1), and Ekman and Frankenhaeuser (Note 3) always assumed that there was no bias in the transformation of $\mathbf{P}$, and accordingly set $\mathbf{p}=\mathbf{P}$ when estimating $\mathbf{n}$.

According to Equation 6, if $p=P$, then in the reproduction task $(P=1)$ the slope $p^{1 / n}$ must be 1.00. Under these circumstances, the exponent $n$ cannot be estimated. Thus, as long as it is assumed that $\mathrm{p}=\mathrm{P}$, this simple model (Model $\mathrm{A}$ in Eisler, 1975 ) is of no use in the analysis of reproduction data.

Two models have dominated the analysis of ratiosetting data. Ekman (1958), Frankenhaeuser (1960), Ekman (Note 1), and Ekman and Frankenhaeuser (Note 3) have maintained that the variable duration should not be directly compared to the standard duration for the following two reasons. The subject is relatively passive when observing the standard, but is active in the setting of the variable. The standard is always presented before the variable, and therefore the setting of the variable is based on the subject's memory of the standard. According to these investigators, the appropriate comparison is between variable settings based on different ratios of the standard.

If we let $v_{A}$ and $v_{B}$ represent the subjective durations of the variable for experimenter-specified ratios of $P_{A}$ and $P_{B}$, respectively, and $p_{A}$ and $p_{B}$ the subject's tranformation of $P_{A}$ and $P_{B}$, then

$$
\frac{v_{A}}{v_{B}}=\frac{p_{A}}{p_{B}} \text {. }
$$

Substituting Equation 3 in Equation 7, and rearranging terms

$$
\mathrm{V}_{\mathrm{A}}=\mathrm{V}_{\mathrm{B}}\left(\frac{\mathrm{p}_{\mathrm{A}}}{\mathrm{p}_{\mathrm{B}}}\right)^{1 / \mathrm{n}}+\mathrm{c}_{\mathrm{v}}\left[1-\left(\frac{\mathrm{p}_{\mathrm{A}}}{\mathrm{p}_{\mathrm{B}}}\right)^{1 / \mathrm{n}}\right],
$$

where $V_{A}$ and $V_{B}$ represent the stimulus duration of the variable settings. Equation 8 is of the form

$$
\mathrm{V}_{\mathrm{A}}=\mathrm{mV}_{\mathrm{B}}+\mathrm{a} \text {, }
$$

where

$$
\mathrm{m}=\left(\frac{\mathrm{p}_{\mathrm{A}}}{\mathrm{p}_{\mathrm{B}}}\right)^{1 / \mathrm{n}}
$$


and

$$
a=c_{v}(1-m) .
$$

If it is assumed that $p_{A}=P_{A}$ and $p_{B}=P_{B}$, then

$$
m=(1 / 2)^{1 / n}
$$

when half-settings are plotted as a function of reproductions, and also when reproductions are plotted as a function of double-settings. The two functions should have identical slopes. A value of $n$ can be estimated from Equation 11 by taking the logarithm of both sides and rearranging terms:

$$
\mathrm{n}=\frac{\log 1 / 2}{\log \mathrm{m}}
$$

Eisler (1975) adopted a different solution to the analysis of ratio-setting data (Model C). He proposed that the subject does not use the experimenter's standard as his standard. Rather, the subject uses as his standard the subjective value of the total duration minus the subjective value of the variable duration, where total duration refers to the stimulus duration of the standard plus the stimulus duration of the variable. If we let $T$ equal $S+V$, and $t$ represent the subjective duration of $T$, then

$$
\mathrm{v}=\mathrm{p}(\mathrm{t}-\mathrm{v})=\left(\frac{\mathrm{p}}{1-\mathrm{p}}\right) \mathrm{t},
$$

and if the power law is assumed,

$$
t=k_{t}\left(T-c_{t}\right)^{n}
$$

Substituting Equations 3 and 14 into Equation 13, and rearranging terms,

$$
V=T\left(\frac{p}{1-p}\right)^{1 / n}+c\left[1-\left(\frac{p}{1-p}\right)^{1 / n}\right]
$$

for $k_{v}=k_{t}$ and $c_{v}=c_{t}=c$. Equation 15 is of the form

$$
\mathrm{V}=\mathrm{mT}+\mathrm{a},
$$

where

$$
\mathrm{m}=\left(\frac{\mathrm{p}}{1-\mathrm{p}}\right)^{1 / \mathrm{n}}
$$

and

$$
a=c(1-m) \text {. }
$$

A value for $\mathrm{n}$ can be estimated from Equation 16 by taking the logarithm of both sides and rearranging terms:

$$
\mathrm{n}=\frac{\log \left(\frac{\mathrm{p}}{1-\mathrm{p}}\right)}{\log \mathrm{m}} .
$$

The two models for obtaining $\mathbf{n}$ have yielded widely discrepant estimates. For example, Ekman and Frankenhaeuser (Note 3) arrived at an exponent of 1.55 by comparing half-settings to reproductions. Eisler (1976) estimated the exponent for the same set of data to be 1.06 for half-settings and .89 for reproductions. Frankenhaeuser (1960) arrived at an exponent of 1.87 for her half-setting/reproduction comparison, while Eisler (1976) estimated the exponent to be 1.00 for half-settings and .80 for reproduction.

Parenthetically, it is of interest to note that Treisman (1964) argued that Equation 1 represented an arbitrary assumption, and suggested as an alternative, that in the ratio-setting task

$$
\mathrm{v}-\mathrm{s}=\log \mathrm{p} .
$$

He then went on to show that the empirical linear relationship between variable settings and standard durations (Equation 2) was compatible, not with the power law, but with the logarithmic law.

Either comparing variable settings or redefining the standard as the total duration allows $n$ to be estimated from reproduction data. However, both models must assume that $\mathrm{p}=\mathrm{P}$ in order to obtain an estimate of $\mathbf{n}$ from any ratio-setting task. As Eisler (1974) notes, if it is assumed that $p=P$, and if in fact there is a discrepancy between $p$ and $P$, then the estimated value of $n$ will be invalid. It must be remembered that the conclusion that time perception is not veridical rests on the assumption that $\mathbf{p}=\mathbf{P}$.

While considerable ratio-setting data exist in the literature, new data were generated for basically three reasons. In previous ratio-setting studies, each subject contributed few observations, and therefore conclusions about the psychophysical function were usually based on data averaged over subjects. Even in the most comprehensive ratio-setting study (Eisler, 1975), each data point generated by an individual subject is based on a maximum of six observations. The data to be presented in this paper were produced by relatively well-practiced subjects.

Few studies have used more than two ratio-setting tasks, and many have only used one. In the present study, each subject made judgments in four different tasks. 
In most previous studies, the range of standard durations has been large, and often a sharp "break" in the linear relationship between variable settings and standard durations is observed (Eisler, 1975; Ekman \& Frankenhaeuser, Note 3). Since the range of values in a duration discrimination task is, of necessity, small, and since the "breaks" are difficult to interpret theoretically, a fairly restricted range of standard durations was used.

\section{METHOD}

Four paid subjects participated in the experiment. The subject was seated in a dimly illuminated IAC sound-attenuated auditory chamber. Both the standard duration and the variable duration were marked by the on-period of a Sylvania Glow Modulator bulb (R 1131C) driven by an Iconix power supply (Model 6195-4). The bulb was enclosed in a metal box with an aperture of $4 \mathrm{~mm}$ in diameter, subtending a visual angle of approximately $21 \mathrm{~min}$. The auditory warning signal was a $1,000-\mathrm{Hz}$ tone produced by a Wavetek function generator, and was presented to the subject over headphones. The subject terminated the variable duration by pressing a button in the arm of his chair. The presentation and timing of all events and the recording of responses were controlled by a PDP-8/E computer.

Each trial began with a 500 -msec auditory warning signal followed $1 \mathrm{sec}$ later by the standard duration. The variable was presented $750 \mathrm{msec}$ after the standard, and the subject was instructed to terminate the second light when he judged its duration to be some proportion $P$ of the standard duration presented on that trial. The trial length was independent of the variable duration produced by the subject, in that the variable duration plus the intertrial interval was a constant.
There were four phases to the experiment. All subjects went through the phases in the same order. During each phase one of eight possible standard durations was presented on each trial.

Phase 1: Reproduction $(\mathrm{P}=1)$ : The eight standard values ranged from 500 to $2,250 \mathrm{msec}$ in 250 -msec steps (short range). The subject was instructed to terminate the second (variable) light when he judged its duration to be equal to the duration of the standard presented on that trial.

Phase 2: Reproduction $(\mathrm{P}=1)$ : The values of the eight standards from Phase 1 were doubled so that they ranged from 1,000 to 4,500 msec in 500-msec steps (long range).

Phase 3: Half-setting $(P=1 / 2)$ : The eight standard values from Phase 2 were used. The subject was instructed to terminate the second (variable) light when he judged its duration to bè half the duration of the standard presented on that trial.

Phase 4: Double-setting $(\mathrm{P}=2)$ : The eight standard values from Phase 1 were used. The subject was instructed to terminate the second (variable) light when he judged its duration to be double the duration of the standard presented on that trial.

Each session consisted of three blocks of 72 or 96 trials, with a 1-min break between blocks. There were one or two practice sessions at the beginning of each phase. The number of data sessions for each phase is shown in Table 1. Excluding practice sessions, each standard was presented a minimum of 108 times ( 27 times per session for four sessions) during each phase.

No feedback of any kind was given to the subjects during the experiment.

\section{RESULTS}

For each subject, the mean value of the variable setting was determined for each standard duration. These means are recorded in Table 1. In Figure 1, half-settings of the long-range durations (Phase 3)

Table 1

Mean Value of Variable Duration (milliseconds) for Each Subject

\begin{tabular}{|c|c|c|c|c|c|c|c|c|c|c|}
\hline \multirow[b]{2}{*}{ Task } & \multirow[b]{2}{*}{ Subject } & \multirow{2}{*}{$\begin{array}{c}\text { Number } \\
\text { of } \\
\text { Sessions }\end{array}$} & \multicolumn{8}{|c|}{ Standard Duration (msec) } \\
\hline & & & 500 & 750 & 1000 & 1250 & 1500 & 1750 & 2000 & 2250 \\
\hline \multirow[t]{2}{*}{$\begin{array}{l}\text { Reproduction } \\
\text { (Short Range) }\end{array}$} & $\begin{array}{c}\text { N.D. } \\
\text { H.W.B. } \\
\text { S.L.A. } \\
\text { S.K. }\end{array}$ & $\begin{array}{l}5 \\
4 \\
4 \\
4\end{array}$ & $\begin{array}{l}478 \\
739 \\
601 \\
639\end{array}$ & $\begin{array}{l}727 \\
963 \\
867 \\
911\end{array}$ & $\begin{array}{r}963 \\
1185 \\
1141 \\
1160\end{array}$ & $\begin{array}{l}1267 \\
1407 \\
1370 \\
1358\end{array}$ & $\begin{array}{l}1533 \\
1671 \\
1629 \\
1518\end{array}$ & $\begin{array}{l}1812 \\
1926 \\
1866 \\
1678\end{array}$ & $\begin{array}{l}2139 \\
2154 \\
2114 \\
1829\end{array}$ & $\begin{array}{l}2374 \\
2395 \\
2361 \\
1944\end{array}$ \\
\hline & & & 1000 & 1500 & 2000 & 2500 & 3000 & 3500 & 4000 & 4500 \\
\hline \multirow[t]{2}{*}{$\begin{array}{l}\text { Reproduction } \\
\text { (Long Range) }\end{array}$} & $\begin{array}{l}\text { N.D. } \\
\text { H.W.B. } \\
\text { S.L.A. } \\
\text { S.K. }\end{array}$ & $\begin{array}{l}5 \\
5 \\
6 \\
4\end{array}$ & $\begin{array}{r}974 \\
1144 \\
880 \\
1058\end{array}$ & $\begin{array}{l}1520 \\
1501 \\
1494 \\
1558\end{array}$ & $\begin{array}{l}2178 \\
2016 \\
2010 \\
1962\end{array}$ & $\begin{array}{l}2646 \\
2526 \\
2531 \\
2270\end{array}$ & $\begin{array}{l}3164 \\
3068 \\
2998 \\
2621\end{array}$ & $\begin{array}{l}3634 \\
3503 \\
3482 \\
2880\end{array}$ & $\begin{array}{l}4195 \\
3976 \\
3935 \\
3143\end{array}$ & $\begin{array}{l}4694 \\
4392 \\
4425 \\
3312\end{array}$ \\
\hline & & & 1000 & 1500 & 2000 & 2500 & 3000 & 3500 & 4000 & 4500 \\
\hline \multirow[t]{2}{*}{ Half-Setting } & $\begin{array}{c}\text { N.D. } \\
\text { H.W.B. } \\
\text { S.L.A. } \\
\text { S.K. }\end{array}$ & $\begin{array}{l}5 \\
4 \\
6 \\
5\end{array}$ & $\begin{array}{l}530 \\
622 \\
434 \\
294\end{array}$ & $\begin{array}{l}800 \\
795 \\
794 \\
374\end{array}$ & $\begin{array}{r}1049 \\
940 \\
1075 \\
482\end{array}$ & $\begin{array}{r}1340 \\
1219 \\
1324 \\
552\end{array}$ & $\begin{array}{r}1584 \\
1402 \\
1600 \\
666\end{array}$ & $\begin{array}{r}1899 \\
1694 \\
1858 \\
819\end{array}$ & $\begin{array}{r}2175 \\
1961 \\
2080 \\
912\end{array}$ & $\begin{array}{l}2466 \\
2157 \\
2355 \\
1074\end{array}$ \\
\hline & & & 500 & 750 & 1000 & 1250 & 1500 & 1750 & 2000 & 2250 \\
\hline Double-setting & $\begin{array}{c}\text { N.D. } \\
\text { H.W.B. } \\
\text { S.L.A. } \\
\text { S.K. }\end{array}$ & $\begin{array}{l}5 \\
5 \\
6 \\
5\end{array}$ & $\begin{array}{r}986 \\
1356 \\
851 \\
831\end{array}$ & $\begin{array}{l}1384 \\
1768 \\
1178 \\
1213\end{array}$ & $\begin{array}{l}1850 \\
2302 \\
1635 \\
1479\end{array}$ & $\begin{array}{l}2414 \\
2730 \\
2005 \\
1716\end{array}$ & $\begin{array}{l}2791 \\
3169 \\
2483 \\
1824\end{array}$ & $\begin{array}{l}3114 \\
3608 \\
2888 \\
1954\end{array}$ & $\begin{array}{l}3396 \\
4037 \\
3245 \\
2044\end{array}$ & $\begin{array}{l}3617 \\
4531 \\
3560 \\
2119\end{array}$ \\
\hline
\end{tabular}



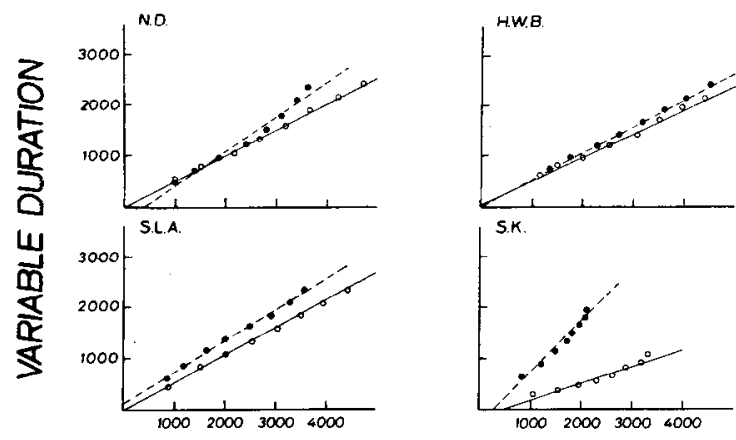

VARIABLE DURATION

Figure 1. Variable setting as a function of variable setting. Filled circles represent reproductions (short range) as a function of double-settings, open circles represent half-settings as a function of reproductions (long range).

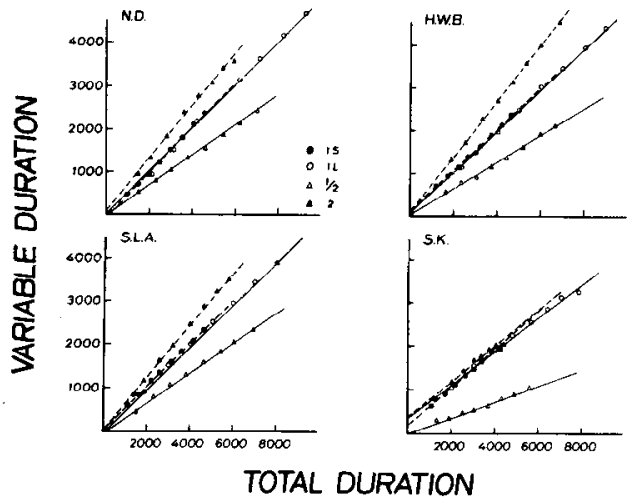

Figure 2. Variable setting as a function of total duration. 15 represents reproductions of the short-duration range, $1 L$ represents reproductions of the long-duration range, $1 / 2$ represents half-settings, and 2 represents double-settings.

are plotted as a function of reproductions of the long-range durations (Phase 2), and reproductions of the short-range durations (Phase 1) are plotted as a function of double settings of the short-range durations (Phase 4). The regression lines for the two variable-variable comparisons are also shown. For no subject are the two lines parallel. The slope and the intercept of each regression line, the coefficient of determination $\left(r^{2}\right)$, and the exponent $n$ are presented in Table 2 . The values of $n$ were determined using Equation 12. For S.K., the slope of reproduction/double-setting function yields an uninterpretable value of $\mathrm{n}$. For the other three subjects, the reproduction/double-setting exponent is consistently larger than the half-setting/reproduction exponent.

The mean variable setting is plotted as a function of total duration (mean variable duration plus standard duration) in Figure 2. The regression lines for each phase are also shown. The slope and intercept of each regression line, the coefficient of determination $\left(\mathrm{r}^{2}\right)$, and the exponent $\mathrm{n}$ are presented in Table 3 . The values of $n$ were determined using Equation 18 and assuming $\mathrm{p}=\mathrm{P}$. The straight line provides an excellent description for three subjects and an adequate description for S.K. However, for no subject is the same value of $\mathrm{n}$ recovered from all four phases. If the assumption that $\mathbf{p}=\mathbf{P}$ is to be maintained, then these data suggest that task demands influence the exponent of the psychophysical function. Such a conclusion is clearly unsatisfactory.

It is interesting to note that the mean of the 16 exponents in Table 3 is .90 . This value is in remarkable agreement with Eisler's (1976) conclusion based on 111 time perception studies. However, what is clear from an examination of Table 3 is that the mean exponent does not provide a satisfactory description of the performance of the individual subjects.

In Figure 3, the mean variable duration is shown as a function of the standard duration along with

Table 2

The Slope and Intercept of Regression Lines Based on the Variable-Variable Model, $\mathbf{r}^{2}$, and $n$

\begin{tabular}{lccrrrr}
\hline Subject & $\mathbf{P}_{\mathbf{A}}$ & \multicolumn{1}{c}{$\mathbf{P}_{\mathbf{B}}$} & Slope & Intercept & \multicolumn{1}{c}{$\mathbf{r}^{2}$} & \multicolumn{1}{c}{$\mathbf{n}$} \\
\hline N.D. & $1 S^{*}$ & 2 & .70 & -288.07 & .978 & 1.94 \\
& $1 / 2$ & $1 L^{\dagger}$ & .52 & -23.37 & .996 & 1.06 \\
H.W.B. & $1 \mathrm{~S}$ & 2 & .53 & 4.54 & .998 & 1.09 \\
& $1 / 2$ & $1 \mathrm{~L}$ & .47 & 39.18 & .992 & .92 \\
S.L.A. & $1 \mathrm{~S}$ & 2 & .62 & 100.20 & .998 & 1.45 \\
& $1 / 2$ & $1 \mathrm{~L}$ & .54 & -21.23 & 1.000 & 1.12 \\
S.K. & $1 \mathrm{~S}$ & 2 & 1.01 & -280.81 & .979 & \\
& $1 / 2$ & $1 \mathrm{~L}$ & .33 & -140.56 & .945 & .63 \\
\hline
\end{tabular}

*IS refers to reproduction of the short range (500-2,250 $\mathrm{msec})$. $\dagger l L$ refers to reproduction of the long range $(1,000-4,500 \mathrm{msec})$.

Table 3

The Slope and Intercept of Each Regression Line Based on Total Duration, $\mathbf{r}^{2}$, and $n$

\begin{tabular}{lllrrr}
\hline Subject & P & Slope & Intercept & \multicolumn{1}{c}{$\mathrm{r}^{2}$} & \multicolumn{1}{c}{$\mathrm{n}$} \\
\hline N.D. & $1 \mathrm{~S}^{*}$ & .524 & -49.65 & 1.000 & 1.07 \\
& $1 \mathrm{~L} \dagger$ & .513 & -13.02 & 1.000 & 1.04 \\
& $1 / 2$ & .356 & -25.71 & 1.000 & 1.06 \\
& 2 & .611 & 110.52 & .997 & .82 \\
H.W.B. & $1 \mathrm{~S}$ & .488 & 124.26 & 1.000 & .97 \\
& $1 \mathrm{~L}$ & .489 & 70.09 & 1.000 & .97 \\
& $1 / 2$ & .312 & 69.18 & .997 & .94 \\
& 2 & .644 & 161.61 & 1.000 & .92 \\
S.L.A. & $1 \mathrm{~S}$ & .500 & 59.58 & 1.000 & 1.00 \\
& $1 \mathrm{~L}$ & .500 & -13.28 & 1.000 & 1.00 \\
& $1 / 2$ & .349 & -22.86 & .999 & 1.04 \\
& 2 & .615 & 12.42 & 1.000 & .83 \\
S.K. & $1 \mathrm{~S}$ & .426 & 207.28 & .994 & .81 \\
& $1 \mathrm{~L}$ & .391 & 353.92 & .993 & .74 \\
& $1 / 2$ & .181 & 31.29 & .993 & .64 \\
& 2 & .420 & 378.32 & .974 & .47 \\
\hline
\end{tabular}

* IS refers to reproduction of the short range $(500-2,250 \mathrm{msec})$. $\dagger 1 L$ refers to reproduction of the long range $(1,000-4,500 \mathrm{msec})$. 


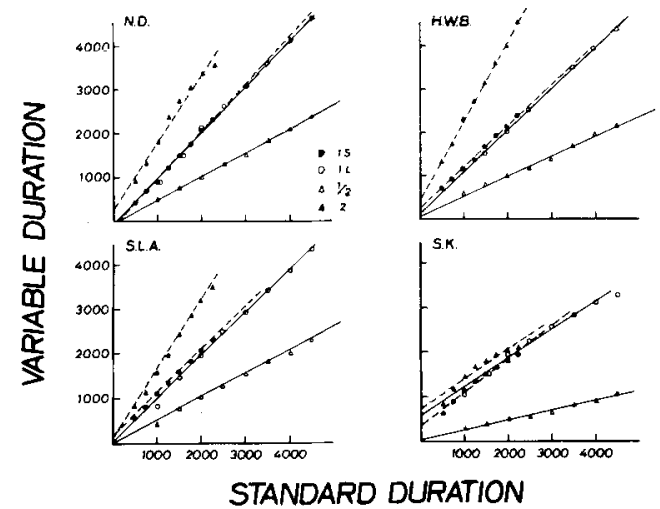

Figure 3. Variable setting as a function of standard duration. is represents reproductions of the short-duration range, if represents reproductions of the long-duration range, $1 / 2$ represents half-settings, and 2 represents double-settings.

the regression lines for each phase. The slope and intercept of each regression line and the coefficient of determination $\left(\mathrm{r}^{2}\right)$ are shown in Table 4. Again, linear functions provide excellent descriptions of the performance of three subjects (N.D., H.W.B., S.L.A.). If it is assumed that subjective time is a linear function of stimulus time, that is, if $\mathrm{n}=1$ in Equation 6, then the slope of the regression line can be taken to represent the ratio of the standard at which the subject sets the variable - that is, an estimate of $p$.

Considering that there was no feedback of any kind, three subjects (N.D., H.W.B., S.L.A.) do remarkably well in setting variable durations which bear the appropriate ratio to the standard duration. The major difficulty appears to be in the double-setting task, where $\mathrm{p}$ underestimates $\mathrm{P}$. The other subject, S.K., consistently adopts a $p$ value smaller than $P$.

From Table 4, it can be seen that, in general, when $p<P$, the intercept is positive, and when $p>P$, the intercept is negative. This relationship suggests that when the subject underestimates the experimenter's ratio $(\mathrm{p}<\mathrm{P})$, he compensates by adding a constant to the transformed standard duration, and when he overestimates the experimenter's ratio $(p>P)$, he compensates by subtracting a constant from the transformed standard.

\section{DISCUSSION}

It is not possible to establish the form of the psychophysical function from either of the ratiosetting models, since the value of either $p$ or $n$ has to be assumed. The usual practice has been to fix $p=P$, and to estimate $n$. The conclusion derived from ratio-setting studies, that time perception is not veridical, is as valid as the assumption that $p=P$.

When it was assumed that $p=P$, an invariant estimate of $\mathrm{n}$ was not obtained from the relatively well-practiced subjects in this experiment. The two models yielded different estimates of $\mathbf{n}$, and for each model the value of $\mathrm{n}$ was influenced by task demands. Previously, the variable-variable comparison model had only been used in experiments involving two ratio-setting tasks (Ekman \& Frankenhaeuser, 1957; Frankenhaeuser, 1960). The present data reveal widely discrepant values of $\mathrm{n}$ when more than one variable-variable comparison is made. The lack of invariance in the estimate of $\mathbf{n}$ in the present data strongly suggests a serious inadequacy with the ratiosetting models. An obvious source of difficulty is with the assumption that $p=P$.

The data also emphasize the caution that should be used in basing conclusions on data averaged over subjects. The mean of the 16 exponents derived from the total duration as standard model is .90 , which is identical to the value Eisler (1976) produced from his survey of 111 studies. However, the mean exponent is hardly representative of the performance of the individual subjects in the present experiment. To ensure that the true functional form of the data is not distorted, averaging over subjects should not be done until confidence about the functional form is attained.

If subjective time bears a linear relation to stimulus time, as suggested by the discrimination data and the recent category rating data, then the results of the present experiment indicate that while a subject can accurately set the experimenter's ratio, he does not always do so. When large discrepancies occur, they are in the direction of underestimation $(p<P)$. When the subject does set a smaller ratio, he appears

Table 4

The Slope and Intercept of Each Regression Line Based on Standard Duration and the Value of $r^{2}$

\begin{tabular}{llrrr}
\hline Subject & P & Slope & Intercept & \multicolumn{1}{c}{$\mathbf{r}^{2}$} \\
\hline N.D. & $1 \mathrm{~S}^{*}$ & 1.10 & -103.34 & .999 \\
& $1 \mathrm{~L} \dagger$ & 1.06 & -24.62 & .999 \\
& $1 / 2$ & .55 & -39.55 & .999 \\
& 2 & 1.55 & 306.80 & .983 \\
H.W.B. & $1 \mathrm{~S}$ & .95 & 243.26 & .999 \\
& $1 \mathrm{~L}$ & .96 & 139.14 & .998 \\
& $1 / 2$ & .45 & 103.39 & .993 \\
& 2 & 1.81 & 454.47 & .999 \\
S.L.A. & $1 \mathrm{~S}$ & 1.00 & 119.39 & 1.000 \\
& $1 \mathrm{~L}$ & 1.00 & -24.17 & .998 \\
& $1 / 2$ & .54 & -33.56 & .997 \\
& 2 & 1.60 & 35.33 & .998 \\
S.K. & $1 \mathrm{~S}$ & .73 & 368.86 & .982 \\
& $1 \mathrm{~L}$ & .64 & 595.08 & .981 \\
& $1 / 2$ & .22 & 39.45 & .989 \\
& 2 & .70 & 684.77 & .924 \\
\hline
\end{tabular}

* $1 S$ refers to reproduction of the short range $(5002,250 \mathrm{msec})$. $\dagger 1 L$ refers to reproduction of the long range $(1,000-4,500 \mathrm{msec})$. 
to add a constant to compensate for his underestimation.

The two ratio-setting models explored in the present paper are effectively one-parameter models. The argument for the necessity of multiple-parameter psychophysical models has been made numerous times in the literature. All current discrimination models have at least two parameters, a discrimination parameter and a decision parameter. Many investigators have shown the influence of "nonsensory" variables on magnitude estimations (e.g., Duda, 1975; Poulton, 1968), and there have been a number of recent attempts to develop multiple parameter magnitude estimation models (Curtis, Attneave, \& Harrington, 1968; Curtis \& Mullin, 1975; Green \& Luce, 1974; Luce \& Green, 1974).

Anderson (1974) and Blankenship and Anderson (1976) criticized the ratio-setting method and concluded that it "has little value for scaling purposes, but should instead be studied for its intrinsic interest as a judgmental process"' (Blankenship \& Anderson, p. 172). I think it would be more accurate to conclude that statements about the psychophysical law should not be based on ratio-setting data which have been analyzed in terms of one-parameter models. The only attempt to develop a multiple-parameter model has been by Thomas and Brown (1974), who have presented a very general framework for time perception. A model for the reproduction task was formulated, but other ratio-setting tasks were not explored, and therefore the relationship between $p$ and $P$ was not addressed. The psychophysical law was not specified by the model. Rather, the suggestion was made that various psychophysical functions should be explored in order that time perception data from a number of different psychophysical tasks may be integrated. The development of a multipleparameter model for ratio-setting data would be a definite contribution to the time perception literature.

\section{REFERENCE NOTES}

1. Ekman, G. Subjective power functions and the method of fractionation. Technical Report No. 34, University of Stockholm, 1956.

2. Eisler, H. A note on treatment of ratio setting data for constructing psychological scales. Technical Report No. 54, University of Stockholm, 1958.

3. Ekman, G., \& Frankenhaeuser, M. Subjective time scales. Technical Report No. 49, University of Stockholm, 1957.

\section{REFERENCES}

Allan, L. G., \& Kristofferson, A. B. Psychophysical theories of duration discrimination. Perception \& Psychophysics, 1974, 16, 26-34.

ANDERSON, N. H. Algebraic models in perception. In E. C. Carterette \& M. P. Friedman (Eds.), Handbook of perception (Vol. 2). New York: Academic Press, 1974.

Anderson, N. H. Note on functional measurement and data analysis. Perception \& Psychophysics, 1977, 21, 201-216.

Blankenship, D. A., \& Anderson, N. H. Subjective duration: A functional measurement analysis. Perception \& Psychophysics, $1976,20,168-172$.

Creelman, C. D. Human discrimination of auditory duration. Journal of the Acoustical Society of A merica, 1962, 34, 582.593.

Curtis, D. W., Atrneave, F., \& Harrington, T. A test of a two-stage model of magnitude estimation. Perception \& Psychophysics, 1968, 3, 24-31.

Curtis, D. W., \& Mullin, L. C. Judgments of average magnitude: Analyses in terms of the functional measurement and two-stage models. Perception \& Psychophysics, 1975, 18, 299-308.

CuRTIS, D. W., \& RulE, S. J. Judgment of duration relations: Simultaneous and sequential presentation. Perception \& Psychophysics, 1977, 22, 578-584.

DudA, P. D. Tests of the psychological meaning of the power law. Journal of Experimental Psychology, 1975, 104, 188-194.

EISLER, H. The derivation of Steven's psychophysical power law. In H. Moskowitz, B. Scharf, \& J. Stevens (Eds.), Sensation and measurement. Dordrecht, Netherlands: D. Reidel, 1974.

Ersler, H. Subjective duration and psychophysics. Psychological Review, 1975, 82, 429-450.

Eisler, H. Experiments on subjective duration 1868-1975: A collection of power function exponents. Psychological Bulletin, 1976, 83, 1154-1171.

Exman; G. Two generalized ratio scaling methods. Journal of Psychology, 1958, 45, 287-295.

FrankenhaEuser, M. Subjective time as affected by gravitational stress. Scandinavian Journal of Psychology, 1960, 1, 1-6.

GETTY, D. J. Discrimination of short temporal intervals: A comparison of two models. Perception \& Psychophysics, 1975, 18, $1-8$.

Getry, D. J. Counting processes in human timing. Perception \& Psychophysics, 1976, 20, 191-197.

GREEN, D. M., \& LUCE, R. D. Variability of magnitude estimates: A timing theory analysis. Perception \& Psychophysics, 1974, 15, 291-300.

KiNCHLA, J. Duration of discrimination of acoustically defined intervals in the 1- to 8-sec range. Perception \& Psychophysics, $1972,12,318-320$.

KRISTOFFERSON, A. B. A real-time criterion theory of duration discrimination. Perception \& Psychophysics, 1977, 21, 105-117.

LuCE, R. D., \& GREEN, D. M. The response ratio hypothesis for magnitude estimation. Journal of Mathematical Psychology, 1974, 11, 1-14.

Poultow, E. C. The new psychophysics: Six models for magnitude estimation. Psychological Bulletin, 1968, 69, 1-19.

Thomas, E. A. C., \& Brown, I. Time perception and the filledduration illusion. Perception \& Psychophysics, 1974, 16, 449-458.

Treisman, M. What do sensory scales measure? Quarterb Journal of Experimental Psychology, 1964, 16, 387-391.

(Received for publication May 24, 1978; revision accepted August 31, 1978.) 